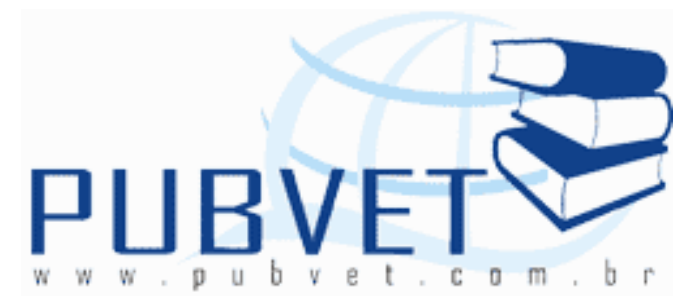

PUBVET, Publicações em Medicina Veterinária e Zootecnia.

\title{
Utilização de levedura (Saccharomyces cerevisiae) na dieta de vacas lactantes
}

\author{
Julyana Machado da Silva Martins ${ }^{1}$; Fernanda Heloisa Litz ${ }^{1}$; Henrique \\ Castilhano²; Danilo Fernandes Campos ${ }^{3}$
}

\author{
${ }^{1}$ Alunas da pós-graduação em Ciências Veterinárias - FAMEV - UFU \\ 2 Zootecnista autônomo \\ ${ }^{3}$ Aluno de graduação em Medicina Veterinária - UFU
}

\section{Resumo}

A bovinocultura leiteira no Brasil é uma atividade de importância econômica e social, tanto de caráter alimentar como na geração de renda e empregos. O aumento da eficiência na produção leiteira está relacionado à melhoria das condições de alimentação. Dessa forma, aditivos alimentares, são utilizados para melhorar o desempenho animal, atuando no rúmen controlando ou modificando o padrão de fermentação, evitando assim distúrbios metabólicos. $O$ interesse pelo uso de microrganismos como aditivos alimentares para vacas leiteiras tem aumentado significativamente nos últimos anos. Um grupo muito utilizado são as leveduras, com destaque a Saccharomyces cerevisiae, apontada como provável responsável pela melhoria no ambiente ruminal, com efeito no pH. Assim objetivou-se, observar a influência da utilização de levedura (Saccharomyces cerevisiae) em dietas de vacas lactantes sobre o aumento da produção de leite.Os dados utilizados neste trabalho foram 
provenientes da Fazenda Quilombo, de propriedade de Winston Frederico Almeida Drumond. A propriedade situa-se na Rodovia MG-154, Km 7, no município de Capinópolis, Minas Gerais. Foram selecionadas vacas da raça Gir Leiteiro P.O. pelo responsável técnico da propriedade.Com o intuito de aumentar a produção de leite foi adicionada à dieta a levedura viva específica do rúmen Saccharomyces cerevisiae CNCM I-1077 (Levucell SC Farm da Lallemand, embalagem de $5 \mathrm{~kg}$ ), com inclusão de 50 gramas/animal/dia, dividido entre os cinco arraçoamentos diários, 10 gramas em cada. Notou-se aumento na produção leiteira dos animais suplementados com a levedura Saccharomyces cerevisiae.

\title{
Use of yeast (Saccharomyces cerevisiae) at the diet of lactating cows
}

\begin{abstract}
The dairy cattle in Brazil is an activity of economic and social importance, both for food and nature in the generation of income and jobs. Increased efficiency in milk production is related to the improvement of power. Thus, food additives, are used to improve animal performance, operating in controlling or modifying the rumen fermentation pattern, thereby preventing disturbances metabólicos. $O$ microorganisms of interest in the use as feed additives for dairy cows has increased significantly in recent years. A group commonly used are yeasts, particularly Saccharomyces cerevisiae, identified as probably responsible for improvement in the rumen, with no effect on $\mathrm{pH}$. So it was aimed to observe the influence of the use of yeast (Saccharomyces cerevisiae) in diets of lactating cows on the increased production of leite.Os data used in this study were derived from the Quilombo Farm, owned by Winston Frederick Adams Drumond. The property is located on Highway MG-154, $7 \mathrm{~km}$ in the city of Capinópolis, Minas Gerais. Cows were selected in Gyr cattle by the head coach of PO propriedade.Com order to increase the production of milk was added to the diet in the rumen specific live yeast Saccharomyces cerevisiae
\end{abstract}


CNCM I-1077 (Levucell SC Farm of Lallemand, pack of $5 \mathrm{~kg}$ ), with inclusion of $50 \mathrm{~g} /$ animal / day, divided between the five day feeding schedule, 10 grams each. Showed an increase in milk production of animals supplemented with the yeast Saccharomyces cerevisiae.

\section{INTRODUÇÃO}

Atualmente, o Brasil apresenta o segundo maior rebanho leiteiro do mundo com cerca de 38 milhões de vacas. E o sexto lugar em produção mundial de leite com 23 bilhões litros/ano, ficando atrás da União Européia, Índia, Estados Unidos, China e Rússia (ANUALPEC, 2011). O que torna a atividade de importância econômica e social para o país, tanto de caráter alimentar como na geração de renda e empregos (ZOOCAL, 2010).

Segundo SOUSA (2012), a atividade leiteira é conhecida como um negócio de lucro e de margens reduzidas, onde apenas aqueles que conseguem reduzir os custos de produção e aumentarem a quantidade e qualidade do leite é que conseguirão ficar na atividade. Com isso o aumento da eficiência na produção leiteira está intimamente relacionado à melhoria das condições de alimentação, e a suplementação é uma das alternativas mais práticas para adequar o suprimento de nutrientes aos requerimentos dos animais (AZEVEDO, 2012).

Devido ao aumento da produção de leite diária por animal, se torna necessário o aumento da concentração dos nutrientes nas dietas, principalmente energia e proteína. Este fato tem ocasionado um alto consumo de rações concentradas pelos animais fazendo-se necessário trabalhar com produtos que melhorem o desempenho animal, como aditivos alimentares, principalmente aqueles que atuem no rúmen controlando ou modificando o padrão de fermentação, evitando assim distúrbios metabólicos e aumentado a eficiência alimentar dos animais (BARBOSA; FARIA; VILELA, 2004).

$O$ interesse pelo uso de microrganismos como aditivos alimentares para vacas leiteiras tem aumentado significativamente nos últimos anos. Um grupo 
muito utilizado são as leveduras, com destaque a Saccharomyces cerevisiae, apontada como provável responsável pela melhoria no ambiente ruminal, com efeito no pH (SANTOS et al., 2006). E consistem em um fator de crescimento de bactérias do rúmen, principalmente celulolíticas (ZEOULA et aL., 2008).

Assim objetivou-se, observar a influência da utilização de levedura (Saccharomyces cerevisiae) em dietas de vacas lactantes sobre o aumento da produção de leite.

\section{MATERIAL E MÉTODOS}

Os dados utilizados neste trabalho foram provenientes da Fazenda Quilombo, de propriedade de Winston Frederico Almeida Drumond. A propriedade situa-se na Rodovia MG-154, Km 7, no município de Capinópolis, Minas Gerais.

Foram selecionadas vacas da raça Gir Leiteiro P.O. pelo responsável técnico da propriedade, que teve como critério de seleção o estágio de lactação, a condição fisiológica e a capacidade de produção, sendo este último observado através do controle leiteiro realizado na propriedade, antes e depois do início do arraçoamento.

Com o intuito de aumentar a produção de leite foi adicionada à dieta das vacas em lactação a levedura viva específica do rúmen Saccharomyces cerevisiae CNCM I-1077 (Levucell SC Farm da Lallemand, embalagem de 5 $\mathrm{kg}$ ), com inclusão de 50 gramas/animal/dia, dividido entre os cinco arraçoamentos diários, 10 gramas em cada.

Algumas observações foram feitas para que o arraçoamento tivesse êxito, dentre elas, o fornecimento de uma dieta de adaptação, a manutenção da dieta sempre fresca no cocho, fornecimento de água limpa e em abundância, realização da análise bromatológica da silagem a ser fornecida para as vacas e suplementação mineral à vontade.

A dieta foi balanceada com o intuito de explorar ao máximo a produção leiteira desses animais. A questão econômica não foi levada em consideração, 
pois o objetivo da criação na Fazenda é a quantidade de leite produzido por animal para participação em exposições e concursos leiteiros, e não a comercialização do leite.

$\mathrm{Na}$ fazenda havia quatro vacas em lactação Gina FIV (primípara), Estância TE de Brasília, Fatia F. Mutum e Caixeta TE F. Mutum aptas a participarem de torneios leiteiros, e estas receberam uma alimentação desafio, em alta quantidade e com alto teor de concentrado, como demonstrado na tabela 1. A alimentação foi divida em cinco fornecimentos diários, visto que, quanto maior o número de arraçoamentos, melhores condições o animal possui de aumentar o seu consumo.

Tabela 1. Dieta fornecida e exigências das vacas em lactação da Fazenda Quilombo.

\begin{tabular}{|c|c|c|c|c|c|c|c|c|}
\hline$\underset{\mathrm{s}}{\stackrel{\text { Ingrediente }}{ }}$ & $\begin{array}{l}\text { MN } \\
(\mathbf{k g})\end{array}$ & $\begin{array}{l}\text { MS } \\
(\mathbf{k g})\end{array}$ & $\begin{array}{l}\text { MS } \\
(\%)\end{array}$ & $\begin{array}{l}\text { NDT } \\
(\%)\end{array}$ & $\begin{array}{l}\text { PB } \\
(\%)\end{array}$ & $\begin{array}{l}\text { FDN } \\
(\%)\end{array}$ & Ca (\%) & $\begin{array}{c}P \\
(\%)\end{array}$ \\
\hline Silagem de & 14,0 & 4,20 & 30,00 & 65,00 & 8,50 & 55,00 & 0,52 & 0,16 \\
\hline Milho & 0 & & & & & & & \\
\hline Feno & 5,00 & 4,60 & 92,00 & 40,00 & 7,00 & 78,00 & 0,40 & 0,20 \\
\hline $\begin{array}{c}\text { Caroço de } \\
\text { Algodão }\end{array}$ & 2,10 & 1,89 & 90,00 & 96,00 & 25,00 & 37,00 & 0,12 & 0,54 \\
\hline $\begin{array}{l}\text { Frileite TL- } \\
22 / 75\end{array}$ & $\begin{array}{c}17,5 \\
0\end{array}$ & 17,50 & 100 & 75,00 & 22,00 & 14,00 & 1,20 & 0,50 \\
\hline Power mix & 4,00 & 4,00 & 100 & 90,00 & 12,00 & - & 0,20 & 0,40 \\
\hline $\begin{array}{l}\text { Suplemento } \\
\text { Mineral }\end{array}$ & 0,10 & 0,10 & 0,10 & . & - & - & 12,30 & 9,00 \\
\hline Total & 42,7 & 32,29 & & & & & & \\
\hline
\end{tabular}

\section{RESULTADOS E DISCUSSÃO}

As exigências dos animais e a diferença em relação à dieta estão dispostas na tabela 2 .

Notou-se que os animais não ingeriam totalmente a ração fornecida, devido à alta quantidade de alimento disponível no cocho, portanto havia uma sobra de aproximadamente $20 \%$ da dieta. Porém, na propriedade a sobra não 
é vista como um desperdício e perdas econômicas, mas sim como sinal de que não faltou alimento ao animal, e a mesma é aproveitada para outras categorias animais.

Tabela 2. Exigências das vacas em lactação da fazenda Quilombo.

\begin{tabular}{lccccc}
\hline Gina FIV (530 Kg PV) & \multicolumn{5}{c}{$\mathbf{( K g )}$} \\
\hline *Exigência (kg) & 12,67 & 3,035 & 5,83 & 0,106 & 0,077 \\
Diferença & 2,22 & 0,497 & 3,22 & 0,052 & 0,004 \\
\hline
\end{tabular}

\begin{tabular}{|c|c|c|c|c|}
\hline $\begin{array}{l}\text { Estância TE de Brasília (600 Kg } \\
\text { PV) }\end{array}$ & & & & \\
\hline *Exigência $(\mathrm{kg})$ & 11,85 & 6,60 & 0,094 & 0,072 \\
\hline Diferença & 1,284 & 2,45 & 0,085 & 0,019 \\
\hline
\end{tabular}

\begin{tabular}{lccccc}
\hline Fatia F. Mutum (620 Kg PV) & & & & & \\
\hline *Exigência (kg) & 12,19 & 2,789 & 6,82 & 0,096 & 0,074 \\
Diferença & 5,23 & 1,343 & 2,23 & 0,088 & 0,020 \\
\hline
\end{tabular}

\begin{tabular}{llllll}
\hline $\begin{array}{l}\text { Caixeta TE F. Mutum (650 Kg } \\
\text { PV) }\end{array}$ & & & & & \\
\hline *Exigência (kg) & 17,08 & 4,181 & 7,15 & 0,149 & 0,106 \\
Diferença & 1,19 & 0,151 & 1,90 & 0,045 & 0,000 \\
\hline
\end{tabular}

Fonte: *NRC (1988).

Realizou-se o controle leiteiro na propriedade durante todo o período de arraçoamento, e se notou um aumento na produção, efeitos esperados com as mudanças na alimentação e manejo. A Tabela 3 demonstra a produção de leite diária de cada animal.

Notou-se aumento na produção leiteira dos animais suplementados com a levedura Saccharomyces cerevisiae observa-se também que alguns possuem uma maior capacidade produtiva que os outros, isso devido à genética mais apurada. Destaca- se que a vaca Caixeta TE F. Mutum, no início do controle, estava com 184 dias em lactação, quando comparado aos animais Gina FIV, Estância TE de Brasília e Fatia F. Mutum, com 25, 120 e 109 dias em lactação, respectivamente, demonstrou maior potencial produtivo. 
Tabela 3. Controle leiteiro da Fazenda Quilombo.

\section{Pesagem de leite em Kg}

\begin{tabular}{ccccc}
\cline { 2 - 5 } Data & Gina FIV & $\begin{array}{c}\text { Estância TE } \\
\text { de Brasília }\end{array}$ & $\begin{array}{c}\text { Fatia F. } \\
\text { Mutum }\end{array}$ & $\begin{array}{c}\text { Caixeta TE } \\
\text { F. Mutum }\end{array}$ \\
\hline $12 / 08 / 2010$ & 18,68 & 17,64 & 19,28 & 32,22 \\
$13 / 08 / 2010$ & 20,88 & 17,76 & 19,03 & 33,00 \\
$14 / 08 / 2010$ & 20,03 & 18,00 & 17,48 & 32,12 \\
$15 / 08 / 2010$ & 21,58 & 19,42 & 20,58 & 31,3 \\
$16 / 08 / 2010$ & 23,6 & 18,77 & 19,94 & 33,09 \\
$17 / 08 / 2010$ & 25,48 & 18,22 & 18,62 & 30,84 \\
$18 / 08 / 2010$ & 24,38 & 17,62 & 18,08 & 29,67 \\
$19 / 08 / 2010$ & 25,01 & 17,06 & 17,34 & 33,84 \\
$20 / 08 / 2010$ & 23,31 & 18,68 & 16,04 & 32,06 \\
$21 / 08 / 2010$ & 23,7 & 19,57 & 16,04 & 33,43 \\
$22 / 08 / 2010$ & 24,35 & 19,66 & 17,74 & 32,64 \\
$23 / 08 / 2010$ & 19,28 & 20,00 & 19,36 & 38,28 \\
$24 / 08 / 2010$ & 25,00 & 20,3 & 23,63 & 34,38 \\
$25 / 08 / 2010$ & 24,23 & 20,94 & 22,44 & 38,42 \\
$26 / 08 / 2010$ & 26,87 & 20,75 & 22,88 & 38,30 \\
$27 / 08 / 2010$ & 25,56 & 20,44 & 25,11 & 39,56 \\
\hline
\end{tabular}

Trabalhos sobre desempenho têm apresentado resultados variáveis quanto ao uso de leveduras para vacas leiteiras. Dentre eles, aumentos na ingestão de MS e na produção de leite e alterações na composição do leite (SANTOS et al., 2006).

As respostas de vacas leiteiras à suplementação com Saccharomyces cerevisiae cepa CNCM I-1077 tem sido positiva. CHEVAUX et al. (2002) utilizaram 60 vacas Holandesas blocadas por ordem de parto e produção de leite e distribuídas aleatoriamente a uma de duas possíveis sequências de dois tratamentos em delineamento de reversão simples (Cross-over): Controle ou 
0,5 g de Levucell da Lallemand. A produção de leite foi $29,9 \mathrm{~kg}$ no controle e $31,2 \mathrm{~kg}$ nos animais suplementados, mostrando que este baixo nível de suplementação com essa levedura foi efetivo para induzir resposta em leite.

Segundo BITENCOURT (2008) o aumento no número total de bactérias ruminais é a principal resposta à suplementação com leveduras e que este aumento na população bacteriana seria capaz de induzir ganhos na digestão da fibra, e consequentemente aumento de produção.

SANTOS et al. (2006) realizaram um experimento com 36 vacas da raça Holandesa aos 300 dias de lactação, produzindo, em média, $18 \mathrm{~kg}$ de leite/dia no meio do período experimental. Os tratamentos consistiram da inclusão de levedura (Levucell SC20 da Lallemand), na quantidade 0,5 g/animal/dia, em dietas contendo dois teores de amido total (22 e 32\%). Neste estudo, a suplementação com leveduras não aumentou $(P>0,05)$ o consumo de matéria seca de vacas no terço final de lactação, independentemente do teor de amido da dieta. Alguns dos possíveis benefícios do uso de microrganismos como suplemento alimentar seriam ambiente ruminal mais estável e maior digestão de matéria seca, favorecendo o consumo de MS. O efeito benéfico da levedura ocorreu apenas nas dietas com alto teor de amido, comprovando que este tipo de aditivo tem maior chance de atuar de forma positiva quando as condições de ambiente ruminal são mais críticas. Entretanto, é difícil explicar o maior teor de gordura no leite de vacas alimentadas com dietas contendo maior teor de amido.

OLIVEIRA et al. (2007) ao suplementar 10 gramas de leveduras para vacas Holandesas em lactação, observaram diminuição na contagem de células somáticas do leite. Estes resultados evidenciam que a suplementação com leveduras pode induzir respostas sobre o sistema imune de ruminantes semelhantes ao observado em animais monogástricos.

DANN et al. (2000) avaliaram o efeito da suplementação com levedura em dietas para vacas Jersey, primíparas e multíparas dos últimos 21 dias préparto até os primeiros 140 dias pós-parto sobre a ingestão de matéria seca e a produção e composição do leite. A suplementação com levedura aumentou a 
ingestão de matéria seca nos últimos sete dias de gestação e nos primeiros 42 dias de lactação. A suplementação também resultou em menor perda de peso corporal e menor utilização da reserva energética corporal para produção de leite para vacas durante o inicio da lactação. Embora as vacas sob suplementação tenham atingido o pico de lactação mais cedo, não houve aumento na produção total nem mudanças na composição do leite. Talvez a suplementação com levedura seja mais eficaz no período de transição e no inicio da lactação, quando o animal encontra-se em estresse mais intenso.

\section{CONCLUSÕES}

Na literatura o uso de levedura (Saccharomyces cerevisiae) em dietas de vacas lactantes tem resultados divergentes. Apesar da quantidade considerável de estudos realizados, os efeitos das leveduras na fermentação ruminal e no desempenho dos animais, assim como o seu mecanismo de ação, não estão conclusivamente definidos.

Contudo existem muitos trabalhos que apontam benefícios no uso de levedura, principalmente em dietas com alto teor de concentrado, onde o ambiente ruminal se encontra em estado mais crítico. Todavia, se torna necessária a padronização de doses suplementadas, e da metodologia utilizada para uma maior eficácia nos experimentos.

\section{REFERÊNCIAS BIBLIOGRÁFICAS}

ANUALPEC. Anuário da Pecuária Brasileira. São Paulo: FNP, 2009. 378 p.

AZEVEDO, Rafael. Manejo e instalações para cria de bezerros leiteiros. On-line. Disponível em: http://www.zootecniabrasil.com.br. Acessado em: 20 de Fevereiro de 2012.

BARBOSA, Fabiano Alvim; FARIA, Gustavo Alves de; VILELA, Herbert. Leveduras Vivas na Nutrição de Bovinos. Biosci. Jornal, Uberlândia, v.20, n.1, p. 143-150, 2004. 
CHEVAUX, E. et al. Effect of Levucell SC CNCM I-1077 suplementation in dairy cow feed on milk production and milk composition. In: Recontres autour des Recherches sur les Ruminants, Paris, France, v.10, p. 391, 2002.

DANN, H.M. et al. Effects of yeast culture (Saccharomyces cerevisiae) on prepartum intake and postpartum intake and milk production of Jersey cows. Journal of Dairy Science, v.83, p.123-127, 2000.

NRC-NATIONAL RESEARCH COUNCIL. Nutrient requeriments

of dairy cattle. Washington: National Academy Press, 1988. 157p

OLIVEIRA, B. M. L., et al. Suplementação de vacas leiteiras com Saccharomyces cerevisiae cepa KA500. In: XVI Congresso de Pós-Graduação da Universidade Federal de Lavras, 2007, Anais... Lavras, 2007.

SANTOS, Flávio Augusto Portela et al. Desempenho de vacas em lactação recebendo dietas com diferentes teores de amido total, acrescidas ou não de levedura (Saccharomyces cerevisiae). Revista Brasileira de Zootecnia, v.35, n.4, p.1568-1575, 2006.

SOUSA, Ronaldo Silva. Sistema de Produção de Leite a Pasto. On-line. Disponível em:http:// www.ceplac.org.br. Acessado em: 21 de Fevereiro de 2012.

ZEOULA, Lucia Maria et al. Digestibilidade parcial e total de rações com a inclusão de ionóforo ou probiótico para bubalinos e bovinos. Revista Brasileira de Zootecnia, v.37, n.3, p.563$571,2008$.

ZOOCAL, R. A inserção do Brasil no mercado internacional de lácteos. Juiz de Fora: EMBRAPA Gado de Leite, 2008. 180 p. 